\title{
Endoscopic ultrasound-guided methylene blue injection to achieve bile duct cannulation after failed ERCP
}

Endoscopic ultrasound (EUS)-guided biliary drainage is an increasingly popular technique for cases of previously unsuccessful endoscopic retrograde cholangiopancreatography (ERCP). It has good results in expert hands, but is a challenging procedure with a significant rate of adverse events [1].

EUS-guided methylene blue cholangiopancreatography is a wireless alternative to the rendezvous technique in benign pancreaticobiliary disease. This interventional EUS-guided technique has been reported anecdotally to facilitate pancreatic duct and common bile duct access [2-4]. Recently, our interventional endoscopy unit published a case series with good results [5]. The purpose of the present report is to elaborate on some important technical details and to clarify some doubts.

The standard procedure includes EUS and ERCP steps, respectively. The EUS part is as follows. i) Advance of a linear array echoendoscope and identification of the duct. Both long and short scope positions are allowed. ii) Checking for interposing vessels using Doppler. iii) EUSguided duct puncture from the gastrointestinal (GI) tract with a 22-gauge needle, which has been prepared without the stylet and purged with saline serum. iv) Aspiration of fluid (bile, pancreatic) before injection. v) Obtaining ductography: slow, careful injection of dilute contrast (with physiological saline solution [SSF]; 1:1). vi) EUS-guided colorant injection: slow, meticulous injection of dilute colorant (methylene blue plus SSF; 1:9); a total amount of $5-15 \mathrm{~mL}$ should be enough, depending on the duct diameter. After this last step, if the ductogram is less visible, due to the dilution effect, an additional amount of contrast $(3-5 \mathrm{~mL})$ can be injected, to ensure a well-marked "road map."

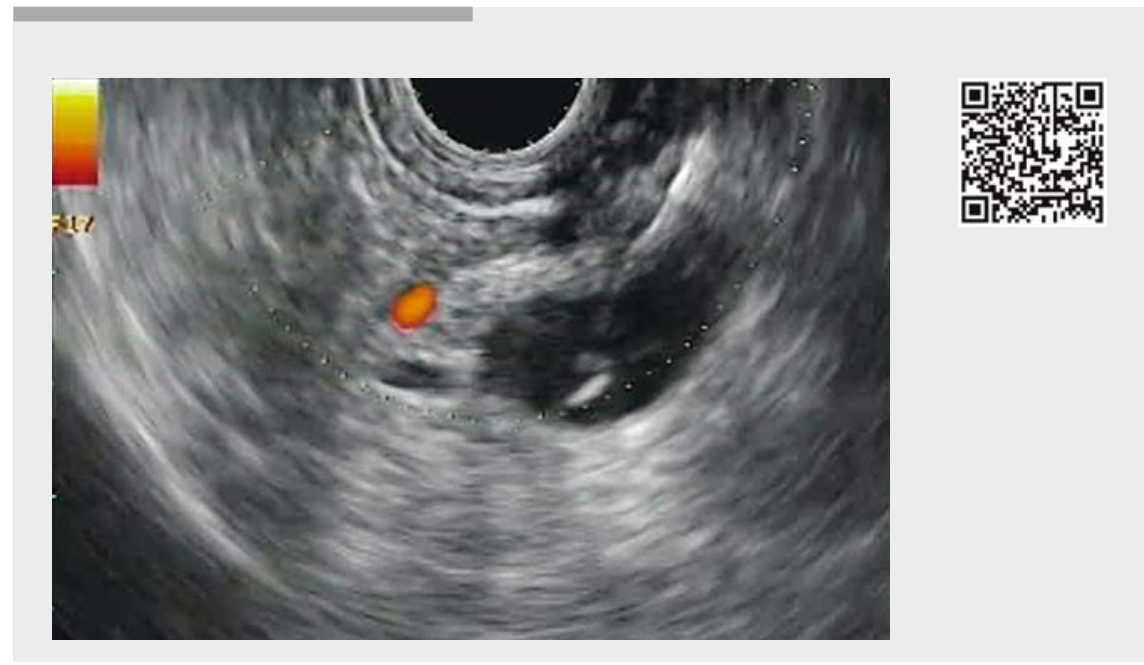

Video 1 An 86-year-old woman presented with cholangitis, and magnetic resonance imaging showed choledocholithiasis. Endoscopic retrograde cholangiopancreatography (ERCP) was attempted but the papillary orifice could not be identified. Subsequently, endoscopic ultrasound-guided cholangiography was performed. A transduodenal puncture of the bile duct was made using a 22 gauge needle. First, a cholangiogram was obtained. Then, $5 \mathrm{~mL}$ of diluted methylene blue was injected. The papillary orifice was identified by methylene blue flow, and bile duct access was then achieved via ERCP.

The ERCP part is as follows. A duodenoscope immediately replaces the echoendoscope. Under endoscopic view, the papillary orifice is identified by methylene blue flow and bulge effect ( $\triangleright$ Fig. 1; - Video 1). Finally, duct cannulation is attempted using sphinctertome wire-guided cannulation, preferably small-diameter ERCP catheters (i.e. 3.9 Fr), or using pre-cut techniques (i.e. needle-knife). This part is challenging; expertise in challenging ERCP procedures is mandatory.

Endoscopy_UCTN_Code_TTT_1AS_2AD

\section{Competing interests}

None
The Authors

Carlos Rodríguez-Escaja ${ }^{1}$, Claudia F.

Consiglieri ${ }^{1}$, Joan B. Gornals ${ }^{1,2}$

1 Endoscopy Unit, Department of Digestive Disease, Hospital Universitari de BellvitgeIDIBELL, Barcelona, Catalonia, Spain

2 Faculty of Health Sciences, Universitat Oberta de Catalunya, Barcelona, Spain

Corresponding author

Joan B. Gornals, MD, PhD

Endoscopy Unit, Department of Digestive Diseases, Hospital Universitari de BellvitgeIDIBELL (Bellvitge Biomedical Research Institute), Feixa Llarga s/n, 08907 L'Hospitalet de Llobregat, Barcelona, Catalonia, Spain

Fax: +34-93-2607681

jgornals@bellvitgehospital.cat 

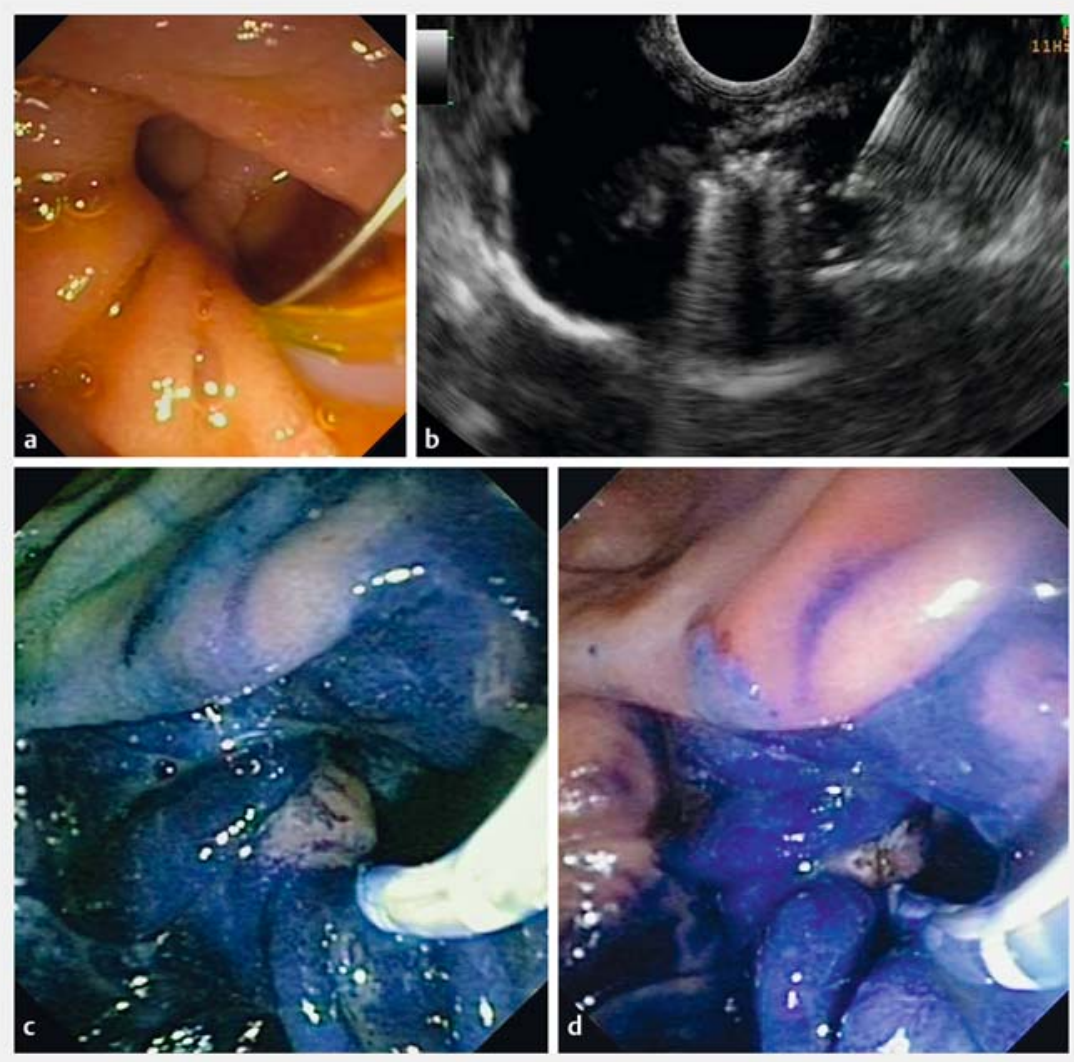

-Fig. 1 Endoscopic ultrasound-guided methylene blue cholangiopancreatography. a Duodenal diverticulum with unidentifiable papilla. b Endoscopic ultrasound-guided methylene blue injection. c, d After methylene blue and saline solution injection, an image of bulge and colorant flow facilitates location and cannulation of the papilla.

\section{References}

[1] Poincloux L, Rouquette O, Buc E et al. Endoscopic ultrasound-guided biliary drainage after failed ERCP: cumulative experience of 101 procedures at a single center. Endoscopy 2015; 47: $794-801$

[2] Park SH, De Bellis M, McHenry L et al. Use of methylene blue to identify the minor papilla or its orifice in patients with pancreas divisum. Gastrointest Endosc 2003; 57: 358 363

[3] Carrara S, Arcidiacono PG, Diellou AM et al. EUS-guided methylene blue injection into the pancreatic duct as a guide for pancreatic stenting after ampullectomy. Endoscopy 2007; 39: E151 - 152

[4] Elmunzer B], Piraka CR. EUS-guided methylene blue injection to facilitate pancreatic duct access after unsuccessful ERCP. Gastroenterology 2016; 151: 809-810

[5] Consiglieri CF, Gornals JB, Albines G et al. EUS-guided methylene blue cholangiopancreatography for benign biliopancreatic diseases after failed ERCP. Gastrointest Endosc 2016; 84: $152-157$

\section{Bibliography}

DOI https://doi.org/10.1055/s-0043-113553

Published online: 5.7.2017

Endoscopy 2017; 49: E219-E220

(c) Georg Thieme Verlag KG

Stuttgart · New York

ISSN 0013-726X

\section{ENDOSCOPY E-VIDEOS \\ https://eref.thieme.de/e-videos}

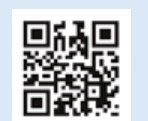

Endoscopy E-Videos is a free access online section, reporting on interesting cases and new techniques in gastroenterological endoscopy. All papers include a high quality video and all contributions are freely accessible online.

This section has its own submission website at

https://mc.manuscriptcentral.com/e-videos 